\title{
The Solution of Environmental Problems and the Dynamics of Demographic Processes in Industrialized Regions
}

\author{
Anton Bel'kov ${ }^{1,}$, , Vladimir Zolotukhin ${ }^{1}$, Natalia Zolotukhina ${ }^{1}$, Natalia Sedina $^{1}$, and Marina \\ Kozyreva $^{1}$
}

${ }^{1}$ T.F. Gorbachev Kuzbass State Technical University, Kemerovo, Russian Federation

\begin{abstract}
The article analyzes the relationship of solving environmental problems with the dynamics of demographic processes in industrialized regions. The attention is focused on the fact that social policy, development of social infrastructure, as well as its relevance depends on the demographic processes taking place at the regional level. Especially important to improve the legal framework for the development and disclosure of human potential, regional investment attractiveness, which will ultimately contribute to the stabilization of the demographic and sociocultural situation both at the professional and daily levels. In this regard, attention is drawn to the fact that the disclosure of labor potential is impossible without taking into account the interests of the business community in educational technologies, in which, in the regional labor market, not only specialists with a narrow set of practical skills, but also with a wide range of fundamental training are in demand. The purpose of the development of the dominant regional segment of large business (coal companies, holdings, etc.) is the introduction of new technics, improvement of technologies, etc. in the field of mining and processing of minerals to level of competitive, environmentally «clean» product not only for foreign markets, but also for domestic consumers. The economic niche of small and medium-sized businesses are enterprises of social and infrastructure sectors of the economy. Related to this are issues of staffing, social and socio-cultural problems in the industrial development of the regions.
\end{abstract}

\section{Introduction}

The environmental situation in the Russian Federation in the today's modern socialeconomic situation can hardly be called prosperous. Regional specificity, especially in industrialized regions, is characterized by a number of serious problems, such as contamination of air, water, soil, radioactive contamination, etc. The Russian Federation has all possible sources of environmental pollution, such as electricity, ferrous and nonferrous metallurgy, oil production and refining, chemical, gas and coal industries. Hence the emergence of various socio-economic risks and social tensions, the deleting of which is

${ }^{*}$ Corresponding author: kemerovo text@mail.ru 
associated with the resolution of the demographic problems associated with the Russian mentality [1], social-economic situation $[2,3]$, the solution of technological problems in the field of innovative development [4], as well as various methodological and organizational approaches to solving environmental problems [5].

\section{Material and Method}

In the framework of the study, the relationship of solving environmental problems with the dynamics of demographic processes in the industrialized regions is paid attention to the implementation of «cultural capital» (R. Solow) in terms of reducing social risks and overcoming socio-cultural contradictions (A. S. Akhiezer) in the framework of making compromise decisions to achieve regional socio-economic stability. Issues related to retraining of employees and transformation of their consciousness are considered within the framework of the system of transforming education (Bowd R., Gordon I., Elias D.), an important component of which is a critical rethinking of approaches to environmental consciousness. In the description of modern trends and principles of functioning of various aspects of the relationship of solving environmental problems with the dynamics of demographic processes in the industrialized regions used methods: rational and logical analysis, structural and functional approach, conceptual analysis, historical and logical comparison, generalization, method of hypotheses with their subsequent verification, as well as methods of correlation analysis.

\section{Results and Discussion}

Studies Yale Center for Environmental Law and Policy at Yale University periodically generate the Environmental Performance Index (last time 2018) as a combined indicator of the state's achievements in terms of the state of the environment and natural resources management. For Russia, it is only 63.79 points, which corresponds to 52 out of 180 places in the environmental ranking of States [6]. In various regions, in particular in the Kemerovo region, there are all the main components that have a negative impact on the environment industry. First of all, it is the dominant regional segment of large business (coal companies, holdings, etc.), a significant level of concentration of objects which is located in the SouthWestern and Western parts of the region. Infrastructure feature is the presence of high-class production hazards.

Air pollution adversely affects the ecological situation of the region as a whole, living organisms and vegetation in particular. The main source of pollution of the atmosphere with dust is the conduct of open development, sorting and transportation of coal. Gas changes in the composition of air occur mainly due to the receipt of harmful toxic impurities contained in the rock mass into the atmosphere during underground oxidation processes, mine fires and methane explosions. For the Siberian Federal district, a characteristic situation in 2017 was that «the share of the population living in unfavorable conditions from air pollution throughout the Federal district was $42 \%$ » [7]. Coal mining is associated with the transformation of vast areas of land, the destruction of the geological structure of the soil and leads to the complete disappearance of the fertile layer of the earth. Coal mining enterprises use hundreds of hectares of land for their work, and therefore as a result of their functioning, the relief and ecosystem of large areas of the region changes, forests are cut down, many natural landscapes are flooded or dried up. All this requires careful study of the regulatory framework in the field of environmental protection, adaptation of environmental standards to modern technological conditions of production development. First of all, it concerns the formation of ecological consciousness of the 
population and the creation of conditions for improving the "quality of life", contributing to the comprehensive development of human potential and stimulating people in their daily lives (management, labor, everyday, etc.) [8] to comply with the requirements of environmental norms and standards.

Adopted at the legislative level, environmental standards, first of all, have technological features of their application, which, in turn, implies a certain culture of their application. Depending on the subjects of application (public authorities, local governments, employers, employees, etc.), their General culture, the implementation of «cultural capital» in terms of critical conditions R. Solow. It is worth noting that the action of the «socio-cultural law» (A. S. Akhiezer) allows to predict and overcome social conflicts, because «the observance of the unity of social relations and culture is a vital imperative, which is the law of reproductive activity» [9, p. 482]. Effective overcoming of social contradictions allows to reduce the level of social tension in the society, which has arisen as a result of concrete practice of implementation of existing environmental standards. The General level of ecological culture as a whole contributes to the harmonization of the system «naturesociety» in the framework of coevolution [10]. In our view, the reflection of the culture of application of environmental standards can be seen at the regional level.

One of the mechanisms for the removal of socio-cultural and social tensions is the adoption and implementation of the state program «Ecology, subsoil use and rational water use» for 2017-2021 [11]. Its objectives, in particular, include sustainable provision of the economy with mineral resources, and the task is «to reduce the overall anthropogenic impact on the environment by improving the environmental efficiency of the economy» and «conservation and restoration of biological diversity of the Kemerovo region». Attention is paid to the effective use and reproduction of mineral resources, as well as the effectiveness of public administration in the field of ecology and subsoil use.

From the point of view of changes in the regulatory framework, which contributes to changes in the environmental situation, it should be noted the amendments made in 2017 to the Federal law of 30.03.1999 № 52-FZ «On sanitary and epidemiological welfare of the population», establishing standards for the calculation and assessment of risks to human health. This allows the gradual introduction of a risk-based approach in the environmental safety management system. Medical institutions controlled by state structures are involved in this process. The result of their joint activities is the resolution «On the use of risk assessment methodology for quality environmental and public health management in the Russian Federation», etc. [7]

The situation around single-industry towns, their development and functioning deserves special attention, since most coal enterprises (mines, sections, etc.) are concentrated in them. They are the city-forming, and historical accumulation of social problems in the field of underfunding, and in some cases of «optimization» of medicine, education, culture, etc. leads to escalate the level of social tension. The negative role, in this case, belongs not only to representatives of local business structures, but also to municipalities as carriers of the state model of management. It is a question of implementation of strategy of minimization of expenses on reproduction of the human capital, the social transformations [12] occurring in the conditions of implementation of projects economically significant for the state, but exploiting for this purpose the available potential within the local labor market.

The objectives of the priority program «Integrated development of single-industry towns» aimed at the strategic development of single-industry towns in Russia until 2025 have not been achieved. The reason for this is not only its early completion (January 1 , 2019), but, as noted by the Accounts Chamber of the Russian Federation, and the lack of «strategic national priorities» [13]. These include: the lack of a «diversified approach to state support of single-industry towns depending on their socio-economic and geographical characteristics», the loss of the most qualified personnel who are forced to leave due to the 
lack of prospects for changes in the field of social infrastructure policy, as these workers were the basis and prospects for the development of city-forming enterprises. This aspect is a significant brake on the implementation of the diversification program as one of the innovative mechanisms [14] of social-economic and socio-cultural development of singleprofile territories at the regional level.

The current environmental situation requires the adoption of operational decisions that would be a compromise for all stakeholders (public authorities and management, business leaders, employees, the public, etc.). An important aspect, in this case, is the solution of the problem of adaptation of workers of industrial (coal) enterprises to meet the requirements of modern environmental standards, because it depends on the individual worker the final implementation of all regulations. Successful adaptation can be considered if the person is satisfied with the quality of the new social space and acquires a higher social status in an environment with changed conditions (claims).

Features of ecological consciousness are determined not only by the system of value orientations, but also differentiated depending on belonging to a certain social group. The content base of ecological consciousness depends on many factors, among which there are professional activities and functional orientation of consciousness. Transformation of consciousness of workers in the field of environmental consciousness takes place within the framework of the system of transforming training. It is aimed at the "perspective transformation" of the personality, which has three dimensions: psychological (changes in the understanding of oneself); value (revision of the belief system) and behavioral (changes in lifestyle) [15].

Transformative learning is the expansion of consciousness through the transformation of the basic picture of the world and the characteristics of their individuality, while transforming learning is facilitated by controlled processes, such as gaining access to the symbolic content of the subconscious and critical analysis of the hidden prerequisites [16]. An important component of transformative learning for the individual is to change his or her frame of mind by critically rethinking beliefs, and by consciously creating and implementing plans that will lead to new ways of defining worldview paradigms. This process is fundamentally rational and analytical [17]. All this, ultimately, contributes to the change in the criteria of economic behavior aimed at the effective use of the principles of sustainable development [18] and adaptation of environmental and economic indicators of industrial enterprises [19] in mining regions, as well as the formation of innovative sociocultural practices in the field of ecology and environmental consciousness.

\section{Conclusion}

The cyclical development of the Kuzbass economy has a direct impact on the environment. Due to the decline in production in the mid-and late 90-ies of XX century in the region has improved the environmental situation. But the relative industrial and economic growth in the early 2000s again raised the issue of improving the conditions for the creation of environmental safety of the industrial region. Currently, the region is carrying out activities to improve the environmental condition, which indicates the desire for the realization and protection of human rights to a favorable environment and partial realization of the need for environmental safety [20, p. 8-9], which will ultimately contribute to the formation of environmental awareness and the introduction of various programs in enterprises for environmental training aimed at improving the overall environmental culture of the population engaged in specific environmentally hazardous areas of the economy. 


\section{References}

1. V. Zolotukhin, A, Bel'kov, E. Stepantsova, M. Kozyreva, A. Tarasenko, E3S Web of Conf., 15, 040115 (2017)

2. T. V. Kiseleva, V. G. Mikhailov, G. S. Mikhailov, IOP Conference Series: Earth and Environmental Science, 84, 012044 (2017)

3. T. Gvozdkova, M. Tyulenev, S. Zhironkin, V. A. Trifonov, Yu. M. Osipov, IOP Conference Series: Earth and Environmental Science Current Problems and Solutions, 50:1, 012010 (2017)

4. T. V. Galanina, M. I. Baumgarten, V. G. Mikhailov, T. G. Koroleva, G. S. Mikhailov, IOP Conference Series: Earth and Environmental Science, 50:1, 012030 (2017)

5. D. Marasova, M. Ligatto, D. Cassiti, V. Zolotukhin, E3S Web of Conf, 105, 04025 (2018)

6. The Environmental Performance Index - a combined indicator of Yale Center for Environmental Law and Policy at Yale University (Yale University, Yale, 2018)

7. Report on the state and environmental protection of the Kemerovo region in 2017 (AKO, Kemerovo, 2017)

8. V. Zolotukhin, N. Zolotukhina, M. Yazevich, A. Rodionov, M. Kozyreva, E3S Web of Conferences, 21, 04008 (2017)

9. A. S. Akhiezer, Socio-cultural dynamics of Russia, 1, 804 (1997)

10. Gritskevich, E. F. Kazakov, A. V. Konovalov, International Conference on Research Paradigms Transformation in Social Sciences, 1, 2357 (2017)

11. About the approval of the state program of the Kemerovo region «Ecology, subsoil use and rational water use» for 2017 - 2021 (AKO, Kemerovo, 2017)

12. V. Zolotukhin, O. Zhukova, International Conference on Research Paradigms Transformation in Social Sciences, 1, 1085 (2017)

13. The problems of development of single-industry towns still need to be solved, but at a new level (AKO, Kemerovo, 2019)

14. N. Egorova, N. Zaruba, T. Jurzina, V. Tumin, E3S Web of Conf, 105, 04021 (2018)

15. Boyd, D. Robert, and J. Gordon Myers, International Journal of Lifelong Education, 7:4, 261 (1988)

16. D. Elias, It's time to change our minds: An introduction to transformative learning. ReVision, 20:1 (1997)

17. Mezirow, J. Transformative Learning: Theory to Practice. New Directions for Adult and Continuing Education, 74, 5 (1997)

18. S. Zhironkin, D. Khloptsov, N. Skrylnikova, I. Petinenko, O. Zhironkina, E3S Web Conf., 41, 04010 (2018)

19. V. G. Mikhailov, T. V. Kiseleva, IOP Conference Series: Materials Science and Engineering, 11, 012012 (2017)

20. N. A. Volkov, Special report of the Commissioner for human rights in the Kemerovo region (AKO, Kemerovo, 2017) 